\title{
ANAL YTICAL AND EXPERIMENTAL INVESTIGATION ON EXPLOITING PREFABRICATION IN PIER CONSTRUCTION OF PRECAST BRIDGES
}

\author{
Nikolaos G. Orologopoulos, Vasileios G. Pilitsis, Konstantinos Katirtzoglou, \\ Ioannis A. Tegos and Kosmas-Athanasios Stylianidis \\ Aristotle University of Thessaloniki \\ Faculty of Engineering \\ School of Civil Engineering \\ Laboratory of Reinforced Concrete and Masonry Structures \\ n.orolog@hotmail.com \\ vpilitsi@civil.auth.gr \\ kostaskatir@gmail.com \\ itegos@civil.auth.gr \\ kcstyl@civil.auth.gr
}

Keywords: Prefabrication, refabricated pier, prefabricated crosshead, abutment, experimental.

\begin{abstract}
In the present study, the potential of expanding the use of prefabrication on bridge piers construction is investigated, as so far its use is limited on a portion of the bridge deck, namely the prefabricated girders and the deck panels. Stimuli for this study are the advantages of prefabrication, such as rapidity and convenience in construction and economy as well. The investigation regards any side effects of the suggested construction method concerning safety, serviceability and durability aspects of the final product. Safety concerns flexural and shear resistance, which should particularly be controlled in the construction joints. The critical section of a partially prefabricated pier is undoubtedly located at the bottom of the pier. The response of this section was investigated experimentally. In order to study the response of this type of piers, two specimens were prepared, one representing a conventionally constructed pier and another pier constructed with the suggested method. An analytical investigation of a prefabricated bridge on the main Greek North-South Highway (P.A.Th.E.) was conducted. Specifically, the bridge was studied in two configurations, one with piers constructed with the conventional method and one with piers constructed as suggested. Useful results were obtained by the comparison of the two configurations. Undoubtedly, the conclusions can be regarded as encouraging.
\end{abstract}




\section{INTRODUCTION}

It is commonly known that the most appropriate classification regarding the existing types of concrete bridges is the one that is based on the currently existing construction methods. These methods are five: a) the traditional cast in-situ case, b) the method combining cast insitu case with prefabrication, c) the incremental launching method, d) the balanced cantilever method and e) the self-advancing formwork system for bridge construction with cast in-situ method. The first two construction methods are the most frequently used, while the other three are special cases and are applied when the use of the first two is not applicable.

The criteria for selecting the most appropriate construction method are mainly technical, economical and time-depended. Technical criteria mainly concern the possibility of using scaffolding placed on the ground, which means that the height of the bridge must not exceed $10 \mathrm{~m}$ in order the use of scaffolding to be feasible. When the height is greater than $10 \mathrm{~m}$, the use of prefabrication method is required. The economic criteria mainly concern the construction costs and the time-dependent criteria concern the rapidity of construction offered by the selected method.

Prefabrication, as a bridge construction method, adequately meets the above criteria. The implementation of this method began after World War II and catered for the infrastructure construction of that period. At first implementations, prefabricated bridges consisted of statically independent (in the longitudinal direction of the bridge), simply supported parts of the deck, which caused problems related with functionality and durability, due to the existence of many construction joints. Later implementations of prefabrication included the casting in-situ of a continuous deck slab, the use of which dealt with the two mentioned disadvantages and the seismic requirements. Regarding the piers of this bridge type in past years, hollow rectangular cross-sections were used in cases of large heights, but nowadays hollow circular crosssections are preferred due to their ability to have similar mechanical behavior regardless direction. On the other hand, regardless of the construction method, abutments are isolated from the deck by the use of bearings for alleviating seismic stresses.

Further on to this review, describing the evolution of prefabricated bridges through time, it can be said that till today prefabrication is very limited regarding the entire bridge structural system. This is not an exaggeration because prefabrication concerns only the beams of the deck and the precast deck panels. The other members, such as the cast in-situ slab of the deck, the piers and their crossheads are casted in-situ. It must be said that the casting in-situ in some cases, i.e. in the case of piers, is a very costly and time consuming construction practice.

In the present study, the implementation of prefabrication in the entire bridge structural system is suggested. Being fully aware that the suggestion of a radical reformation requires appropriate documentation, the authors submit within the present study a documentation including experimental and analytical part.

\section{MECHANIZED METHODS OF PIER CONSTRUCTION}

The mechanized methods of pier construction are used when the height of bridge is greater than 15 to $20 \mathrm{~m}$. In this case, due to the impossibility of direct concreting, construction of piers is done segmentally. These methods have the characteristic of elevating the formwork from a manufacturing level to the next. There are essentially two different techniques for elevation of the formwork: a) Sliding formwork method and b) Climbing formwork method.

In the method of the sliding formwork, the pier construction proceeds with small but continuous steps and the parts of formwork are lifted by using an elevation system consisting of: hydraulic jacks, lifting rods and a suspension frame. The other parts of the elevating system 
are: the formwork (of height circa $1.20 \mathrm{~m}$ ), a working platform, ramps for inspection and safety barriers. Construction is carried out continuously, on a 24-hour basis.

In the method of climbing formwork, casting of each segment is done within preassembled, fixed parts of formwork with suitable height (i.e. 3.0 to $6.0 \mathrm{~m}$ ). After hardening of the concrete, the formwork parts are released and elevated to the next level, re-assembled and prepared for the next phase of casting. The elevation of the formwork in this case is significantly discontinuous (in contrast to the sliding formwork method) and the elevating is done by construction cranes or specific devices attached to the system (self-climbing). With the evolution of self-climbing systems, the use of this method became insensitive to the height constraints and crane lifting capacity and competes the method of the sliding formwork regardless of pier height and practically tends to replace it [1].

The existing mechanized pier construction methods are not effortlessly implemented and time consuming processes. Operation is performed on a 24-hour per day and depends on weather conditions and the landscape where the project is founded (access). They require constant concrete production rate and a significant amount of special equipment, which increases the manufacturing cost. Besides that, there are construction issues which make these methods difficult to apply. Such problems are the friction development between concrete and formwork, the pressure of freshly casted concrete on the formwork and the casting progress rate dependence on concrete composition and concrete production rate.

\section{SUGGESTION OF PIER CONSTRUCTION WITH THE METHOD OF PREFABRICATION}

The following sections describe the suggested construction method of piers with exploitation of prefabrication.

\subsection{Description of pier construction methodology}

In the present study the use of prefabrication in piers of prefabricated bridges is suggested. The suggested methodology and the construction method concerns piers of hollow circular cross-section, which as mentioned above, is the most commonly used cross-section as its moment of inertia is the same regardless of direction. The cross-section of the prefabricated pier consists of two hollow circular prefabricated columns, one contained within the other. Between these two columns a void ring is created, which contains the longitudinal reinforcement of the pier and it is casted in-situ (Fig. 1). Figure 1 presents the implementation of the suggested way of pier construction as an alternative method in the case of prefabricated bridges, which is elaborated in the next paragraph. The transverse reinforcement of the crosssection is placed on both prefabricated columns, which are surrounding the cast in-situ segment. The need of facilitating the transfer of prefabricated elements on the project site and their constructability impose the pier to be composed of segments with ideal height of 5-10 m (Fig. 2), taking into account the overall height of each pier. The short length of each segment facilitates the transportation needs of these elements, in contrast to a greater length which incommodes both transportation and construction. 


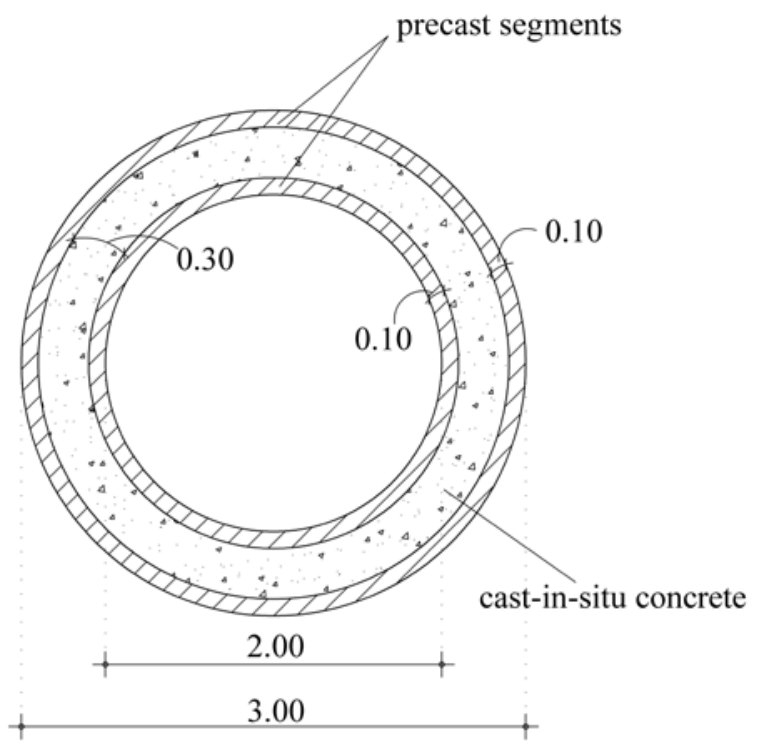

Figure 1: Pier cross-section geometry.

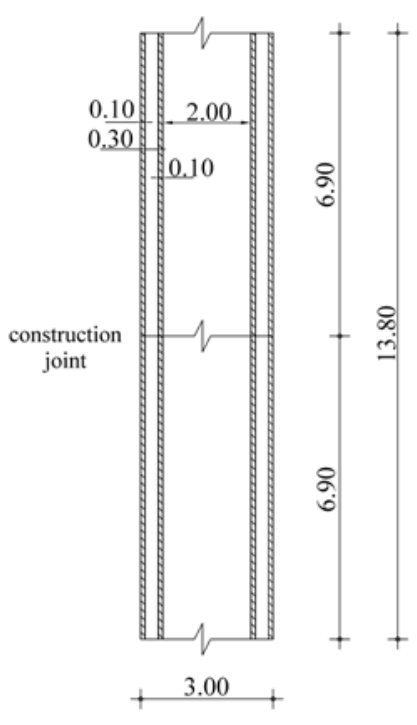

Figure 2: Pier section.

The assembly of individual segments is based on the exploitation of the void between the two precast columns. Initially, at the pile cap (which is casted in-situ), outbound extending rebars with sufficient length are arranged, in order to fit with the geometry of the void between the two prefabricated hollow-circular columns. After placing the first part of the two prefabricated hollow-circular sections, longitudinal reinforcement rebars will be set in the void running the entire height of the first pier part, having a sufficient outbound extending length on the upper part. Subsequently, the void is casted in-situ and the second part of the pier is mounted on the first by repeating the reinforcement and casting in-situ process. This procedure is repeated until the complete assembly of all pier parts, resulting at the end in an integral pier web.

Regarding reinforcement of the hollow-circular columns, it consists of skin and transverse reinforcement against shear, while the longitudinal reinforcement, which is placed in the void, will be the main reinforcement of the cross-section. Indicatively, the length of the outbound extending rebars is $1.75 \mathrm{~m}$, which is based on EC2 provision for rebar diameter Ø25 mm (a commonly used diameter in bridge piers and also in the present case) and a minimum class of concrete C30/37. In this case, reinforcing lap length is calculated by the formula $\mathrm{L}=70 \varnothing=$ $70 \bullet 0.025=1.75 \mathrm{~m}[1]$.

The interaction between the prefabricated segments and the casted in-situ concrete can be improved by embossing the surfaces of the columns in contact with the cast in-situ concrete. In addition, stirrups on the interacting sides of columns (as used for improving the interaction between cast in-situ concrete and prefabricated panels during the construction phase of the deck) can significantly increase the interaction of the prefabricated columns with the cast insitu concrete.

\subsection{Description of the pier crosshead construction methodology}

An example of implementation of the suggested methodology is presented in the present study. The segmentation of the pier crosshead into to symmetrically prefabricated parts is preferable for reasons of crane lifting capacity. The two parts are symmetrical along the long side with dimension $14.20 \mathrm{~m}$. The generated vertical joint does not affect the flexural shear resistance of the crosshead. 
Through holes are formed in each symmetrical part in order to assemble the pier with the prefabricated crosshead. The holes are geometrically located above the casted in-situ void between the two hollow circular columns of the pier.

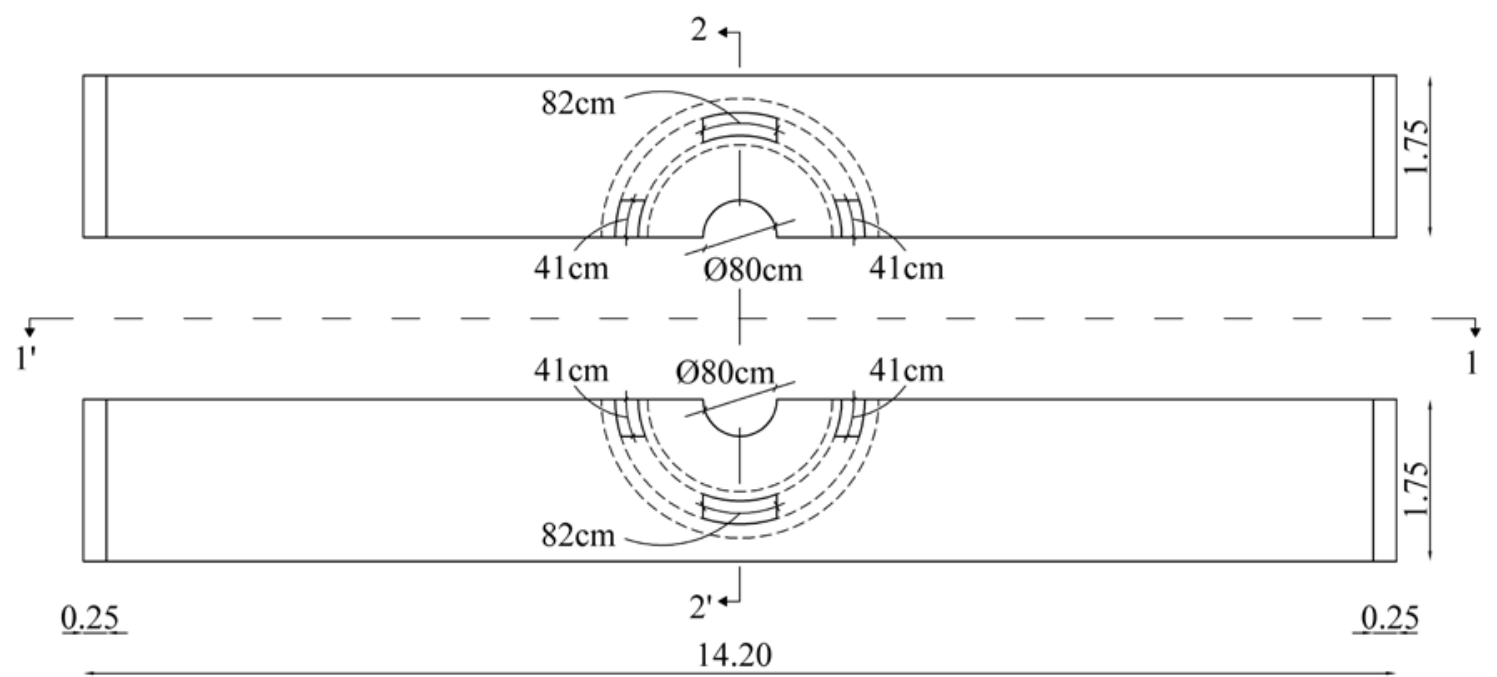

Figure 3: Plan view of prefabricated pier crosshead parts.

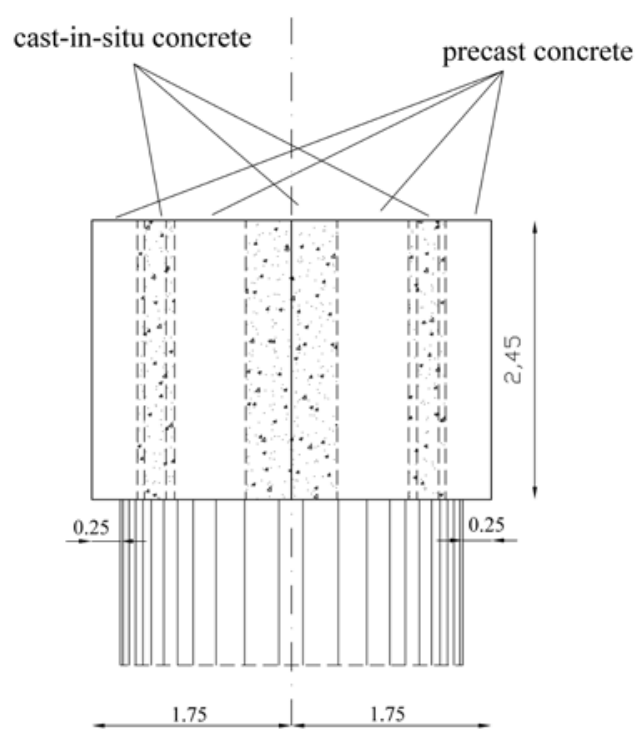

Figure 4: Section 2-2' of the assembled pier crosshead.

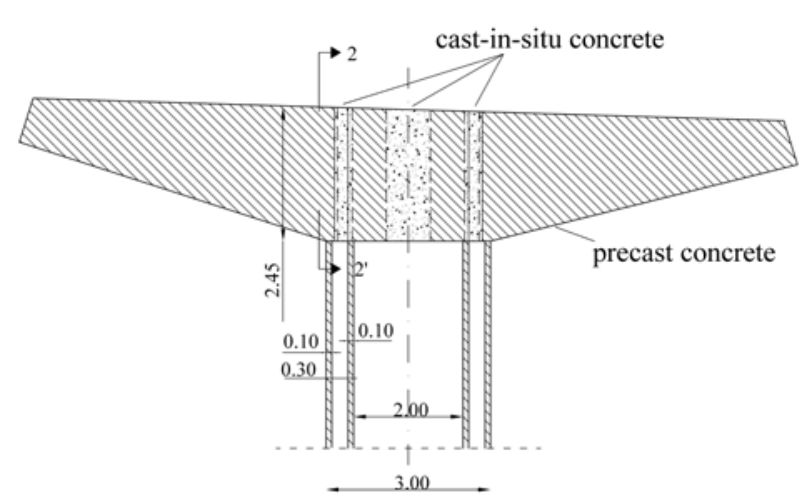

Figure 5: Section $1-1^{\prime}$ of the assembled pier crosshead.

As it is shown in Figures 3 to 5, each prefabricated part has three through holes and an 80 cm diameter semi-circular through hole which serves pier inspection needs. The two holes, which are mirrored to the center of the semi-circular hole, have an arc length dimension of $0.41 \mathrm{~m}$. The arc length dimension of the third hole is $0.82 \mathrm{~m}$.

Once the pier is assembled, the two parts of the pier crosshead are placed onto the pier. The interaction of the two crosshead parts with the pier is achieved by outbound extending 
rebars in the upper pier part, suitable to fit with the geometry of the crosshead through holes. Concrete is casted in the through holes, in order the connection joint between pier and the crosshead to gain integrity.

It must be emphasized that the concreting of the peripheral through holes accommodates only the improvement of the pier-crosshead interaction and does not restore integrity between the two prefabricated crosshead parts, the segmentation of which does not affect the its flexural and shear resistance, as mentioned above.

\section{EXPERIMENTAL INVESTIGATION OF THE SUGGESTED PIER MECHANICAL PROPERTIES}

The purpose of the experimental investigation is to prepare specimens, the testing of which will provide important conclusions regarding the outcome reliability of the suggested construction method. The point at which the experimental research focused is the binding position of the pier prefabricated parts, as this is considered to be the critical cross-section regarding the mechanical behavior during an earthquake.

For this purpose two specimens were prepared: a) a specimen representing a pier constructed segmentally and according to the suggested construction method (Spec1) and b) a specimen representing a pier constructed according to the current pier construction method (Spec2).

Specimen Spec1 consists of two parts. Each part consists of two hollow circular columns having thickness of $5 \mathrm{~cm}$. The inner column has a diameter of $30 \mathrm{~cm}$ and the outer column 60 $\mathrm{cm}$. Each part has a height of $1.75 \mathrm{~m}$. The generated void between the two columns is casted in-situ and has a thickness of $5 \mathrm{~cm}$. Specimen $5 p e c 2$ has a height of $3.5 \mathrm{~m}$ and the thickness of its hollow cross-section is equal to $15 \mathrm{~cm}$. The longitudinal reinforcement of Spec1 is presented in Fig. 6. The reinforcement of Spec2 is placed at the same position as in case of Spec1 but its length is equal to $3.5 \mathrm{~m}$, in contrary with Spec1, in which the longitudinal reinforcement consists of $1.50 \mathrm{~m}$ rebars as shown in Fig. 6. The transverse reinforcement in both cases consists of two coils, an internal coil of $\varnothing 8 / 60 \mathrm{~mm}$ and an external coil of $\varnothing 8 / 50 \mathrm{~mm}$. The transverse reinforcement is designed based on a $50 \%$ greater shear force than the corresponding to the flexural strength of the specimens (Fig. 9). The yield stress of steel used for longitudinal reinforcement was considered equal to $600 \mathrm{MPa}$ in the analytical calculation of their flexural resistance. Accordingly, the class of the concrete was C30/37, and therefore the strength of the concrete was considered to be $30 \mathrm{MPa}$.

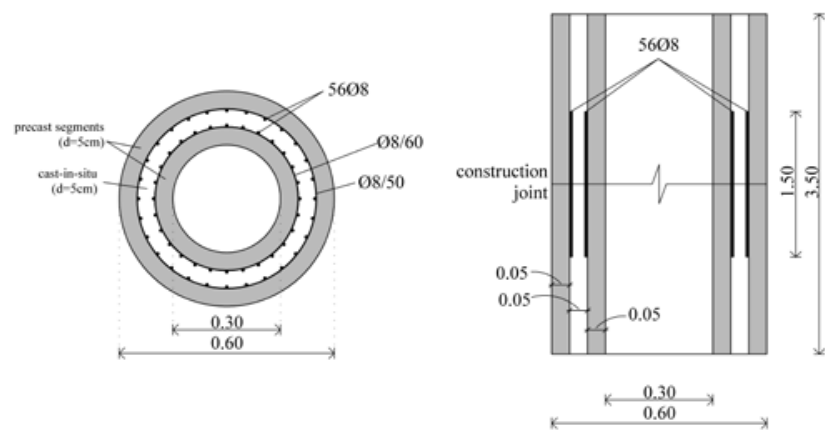

Figure 6: Reinforcement of specimem Spec1.

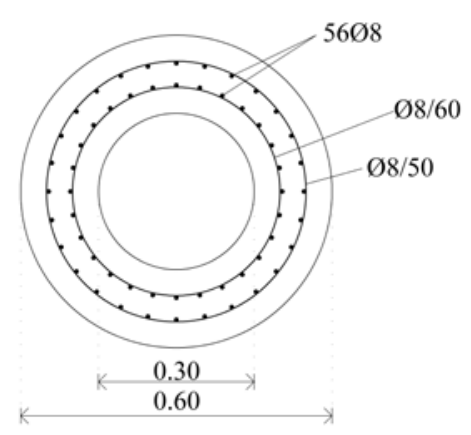

Figure 7: Reinforcement of specimen Spec2.

Each specimen was subjected twice to an incrementally applied point load was applied, in two diametrically opposed points in their mid-length (Fig. 8) until their yield point, which was 
circa 500 - $600 \mathrm{kN}$, as the ultimate load capacity had been calculated previously at about 50tn. Displacement at mid-length of the specimens was recorded by the use of an analog displacement sensor. The static model is presented in Figure 9. The experiment was held in the Laboratory of Experimental Strength of Materials and Structures, Department of Civil Engineering, Aristotle University of Thessaloniki.

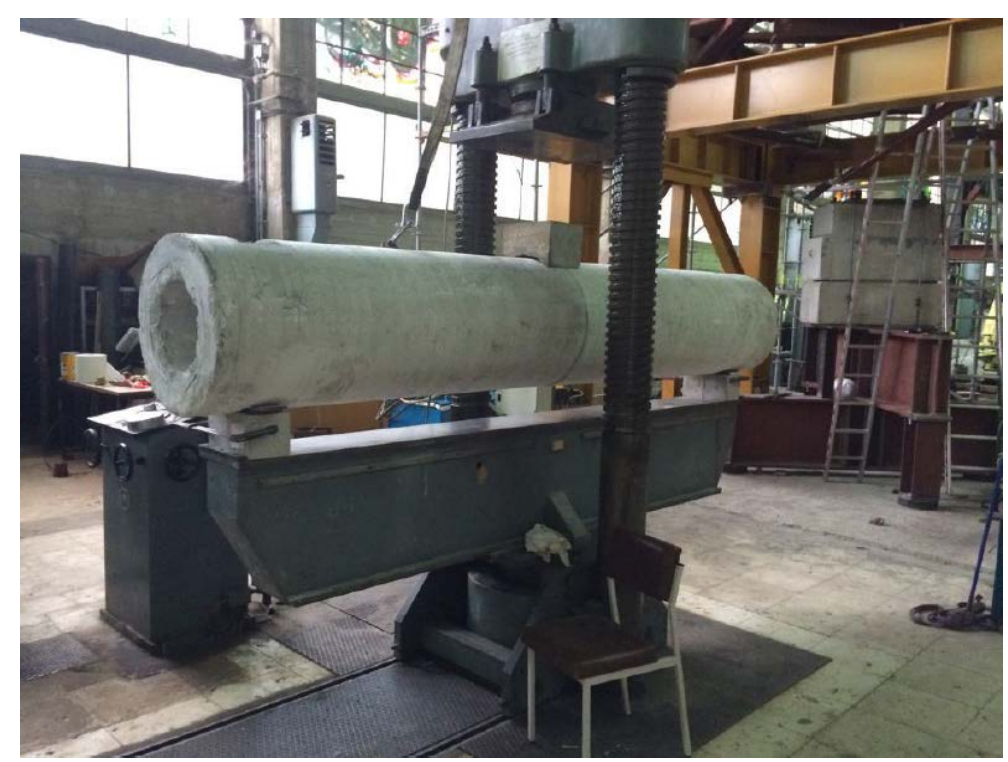

Figure 8: Loading of specimen Spec1 in Laboratory.

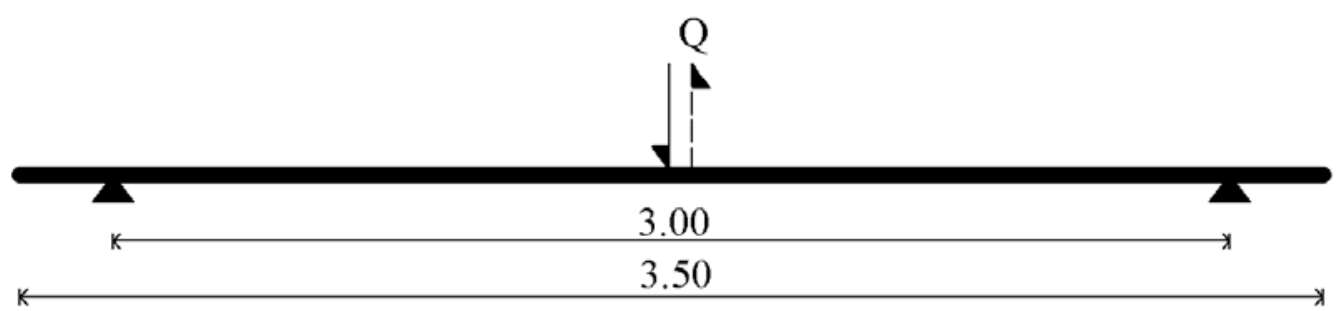

Figure 9: Static model of loading

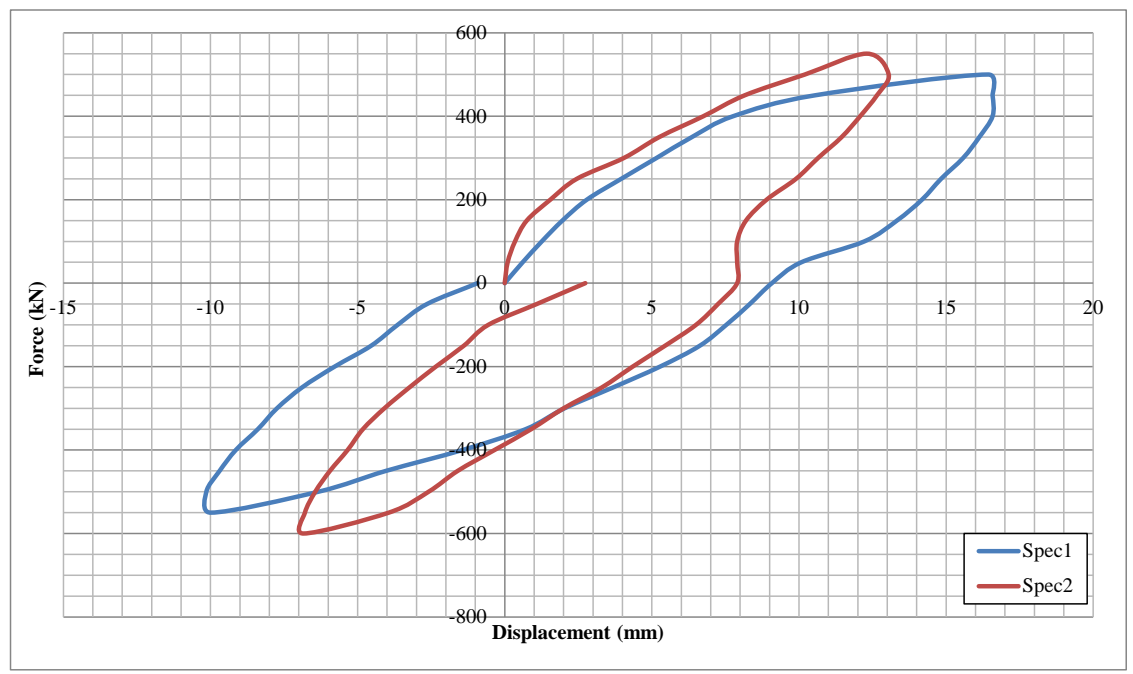

Figure 10: Force - Displacement Diagram for the two specimens. 
As it is shown in Figure 10, the diagram slopes at the state of Stage II (cracked section) are similar. That means that the two specimens have similar flexural stiffness. A comparison regarding the specimen displacement is considered not safe due to imponderables during their preparation.

Regarding the spotted cracks, it must be mentioned that the specimen which represents the prefabricated case (Spec1) did not exhibit external cracks, whereas the specimen which represents the conventional case (Spec2) did exhibit cracks. In particular, this specimen during the first load input, exhibited four vertical cracks at its bottom with length $50 \mathrm{~cm}$ at a load of 500 $\mathrm{kN}$ (Fig. 11-left). During the second load input (at the point diametrically opposed to the first), two vertical cracks with length of $25 \mathrm{~cm}$ emerged at a load level of $450 \mathrm{kN}$ (Fig. 11-right). Two cracks that were formed during the first load input extended through the entire circumference of the section and jointed the two cracks that were formed in the second load input.

The absence of cracks in the segmentally constructed specimen can be credited to its construction procedure. After an earthquake event the problem of sealing the cracks (to prevent the corrosion of the rebars) will not exist.
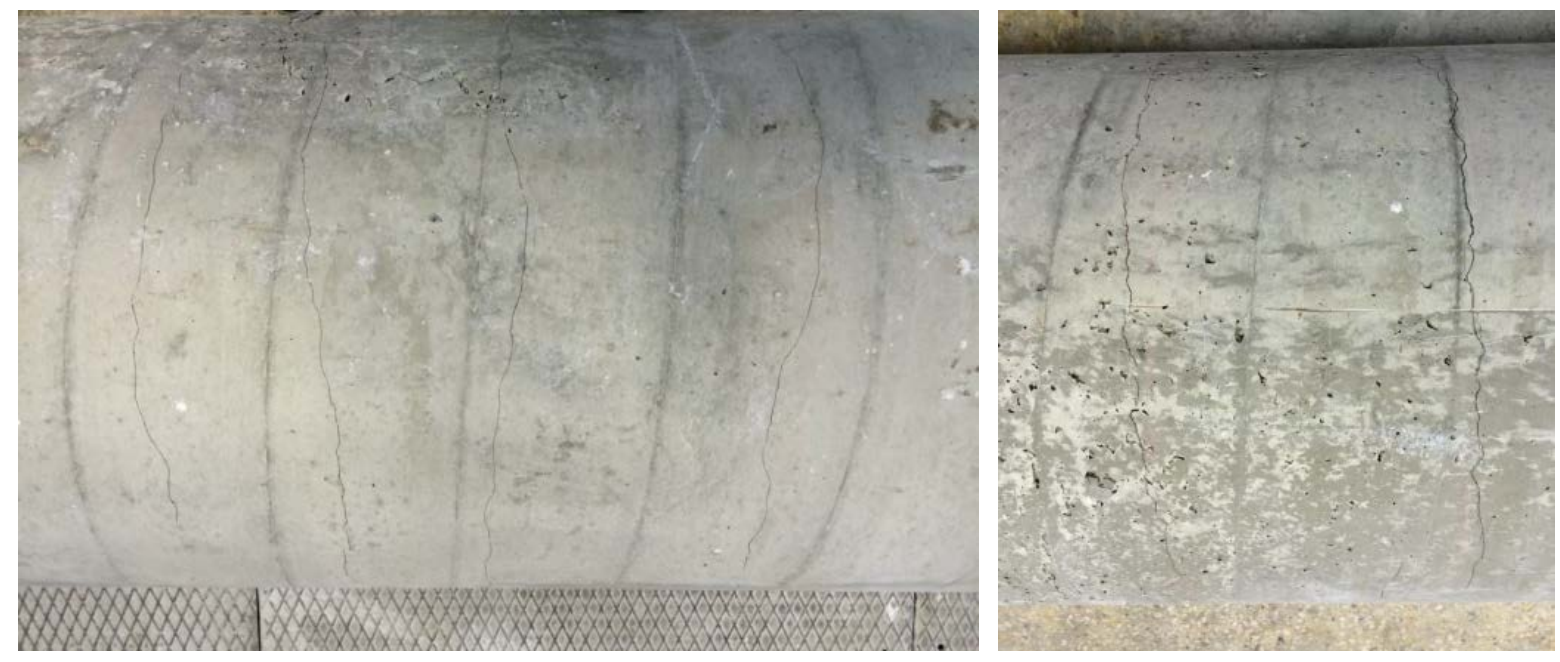

Figure 11: Cracks of specimen Spec2.

\section{IMPLEMENTATION OF PRECAST PIERS AS ALTERNATIVE PROPOSAL}

The proposed piers were applied as an alternative design to an existing precast bridge in P.A.Th.E. motorway in Greece. The longitudinal axis of the bridge (with total length of 177.5 $\mathrm{m}$ ) is on a $3000 \mathrm{~m}$ radius circular arc. The bridge has five spans. The first and the last span have a length of $34.75 \mathrm{~m}$ while the other spans have a length of $36.0 \mathrm{~m}$ (Fig. 11). Each span consists of six prestressed-precast beams and a cast in-situ deck slab of $25 \mathrm{~cm}$ thickness (Fig. 12-a). The piers are single-column of hollow circular cross-section with diameter of $3.0 \mathrm{~m}$. The thickness of the hollow cross-section is $50 \mathrm{~cm}$ (Fig. 12-b). The piers have the form of hammer head with a crosshead of $3.5 \mathrm{~m}$ width. The pier heights range from $9.20 \mathrm{~m}$ to $13.80 \mathrm{~m}$. The deck is supported on piers and abutments through circular elastomeric bearings with diameter of $450 \mathrm{~mm}$, total height of $211 \mathrm{~mm}$ and elastomeric thickness of $99 \mathrm{~mm}$ (9 layers of $11 \mathrm{~mm})$. The abutments have the typical form of seat-type abutments. 


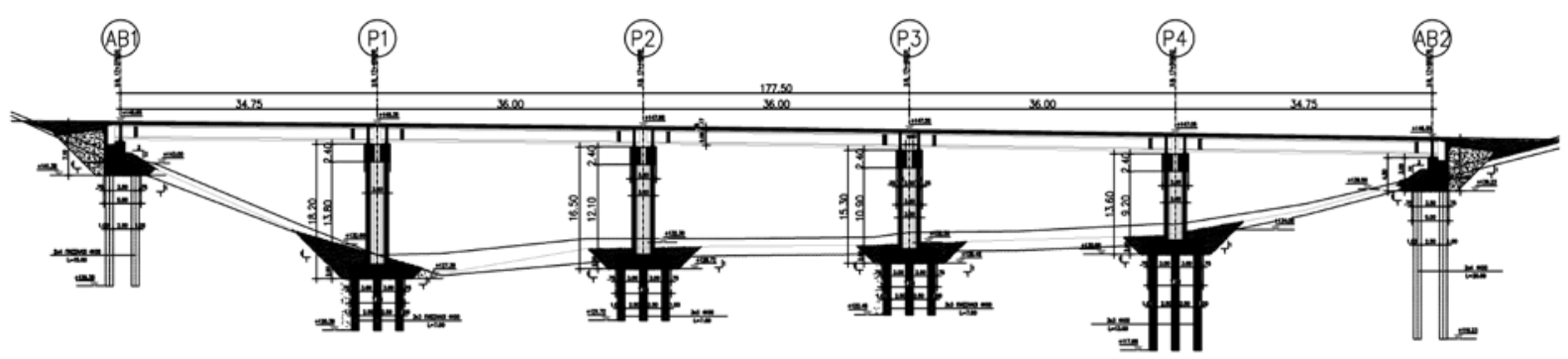

Figure 11: Longitudinal section-cut of the bridge.

The class of the used reinforcing steel is B500C. The class of the prestressing steel is St $1570 / 1770$. The class of the concrete for deck and piers is C30/37 and for abutments C20/25 according to EC2-Part 1 [2] .

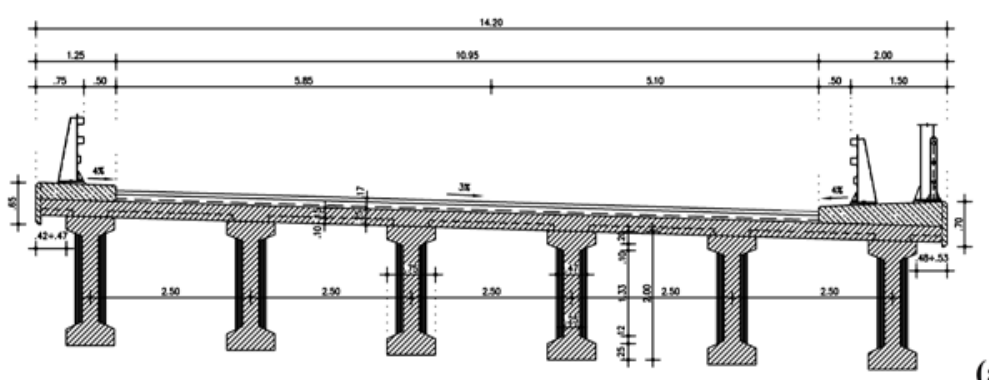

(a)

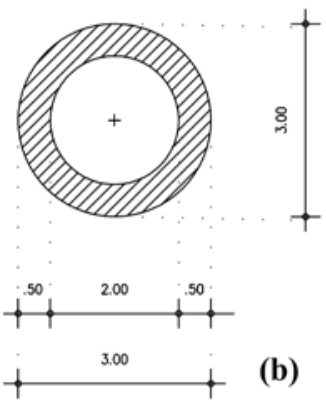

Figure 12: (a) Deck cross-section at midspan, (b) Pier section cross-section.

The bridge is founded on ground type B according to EC8-Part 1 [3] while the seismic design ground acceleration is equal to $0.24 \mathrm{~g}$. The importance factor is consedered equal to $\gamma_{\mathrm{I}}=1.0$. The sugested type of precast piers is applied in the re-designed case of the bridge. Software SAP2000 v.11.0.4 was used for the dynamic spectrum analysis. The design spectra used for the two horizontal directions of the bridge was calculated based on a behavior factor equal to 1.0 due to the presence of elastomeric bearings [4]. A behavior factor equal to 1.0 was considered for the vertical direction as well.

Each pier is composed of two parts (as described in paragraph 3.1) of equal length. Each part consists of two columns with hollow circular cross-sections of $10 \mathrm{~cm}$ thickness. The 30 $\mathrm{cm}$ thick void between the two columns is casted in-situ with self-consolidating concrete and it is containing the longitudinal reinforcement of the cross-section arranged in three circular layers. The reinforcing coil (reinforcement against shear) is placed in the outer prefabricated part. The required longitudinal and transverse pier reinforcement is presented in Tables 1 and 2 respectively. The reinforcement of piers P1 and P2 at bottom and top is presented in Figure 13-a. In the re-designed bridge, the longitudinal and transverse reinforcement of the inner ring is considered secondary. The transverse reinforcement of the prefabricated outer ring receives the total amount of shear force, contrary to the conventional case, in which the inner coil receives part of the developing shear force.

Regarding the effective stiffness of the suggested pier cross-section, it accrued similar to the effective stiffness of the conventional case piers (Fig.13-b). Specifically, the effective stiffness in the re-designed case was equal to $45 \%$ of the uncracked cross-section stiffness, 
while in the existing bridge the effective stiffness was $50 \%$. Therefore the dynamic characteristics and the seismic displacement $\left(\mathrm{d}_{\mathrm{ed}, \mathrm{x}}=20 \mathrm{~cm}\right)$ of the bridge were not different in the two cases.

\begin{tabular}{ccc}
\hline Position & Reinforcement & $\begin{array}{c}\text { Reinforcement } \\
\text { Ratio (\%) }\end{array}$ \\
\hline P1 - bottom & $77 \Phi 25$ & 2.89 \\
P1 - top & $52 \Phi 25$ & 1.95 \\
P2 - bottom & $77 \Phi 25$ & 2.89 \\
P2 - top & $52 \Phi 25$ & 1.95 \\
P3 - bottom & $52 \Phi 25$ & 1.95 \\
P3 - top & $52 \Phi 25$ & 1.95 \\
P4 - bottom & $52 \Phi 25$ & 1.95 \\
P4 - top & $52 \Phi 25$ & 1.95 \\
\hline
\end{tabular}

Table 1: Longitudinal reinforcement of piers of the re-designed bridge.

\begin{tabular}{cc}
\hline Pier & $\begin{array}{c}\text { Transverse } \\
\text { Reinforcement }\end{array}$ \\
\hline P1 & $2 \Phi 14 / 135$ \\
P2 & $2 \Phi 14 / 135$ \\
P3 & $2 \Phi 14 / 135$ \\
P4 & $2 \Phi 14 / 160$ \\
\hline
\end{tabular}

Table 2: Transverse reinforcement of piers of the re-designed.

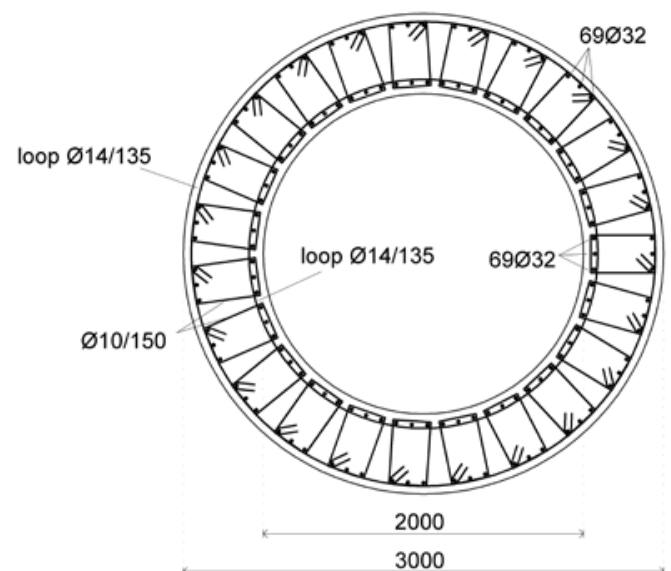

(a)

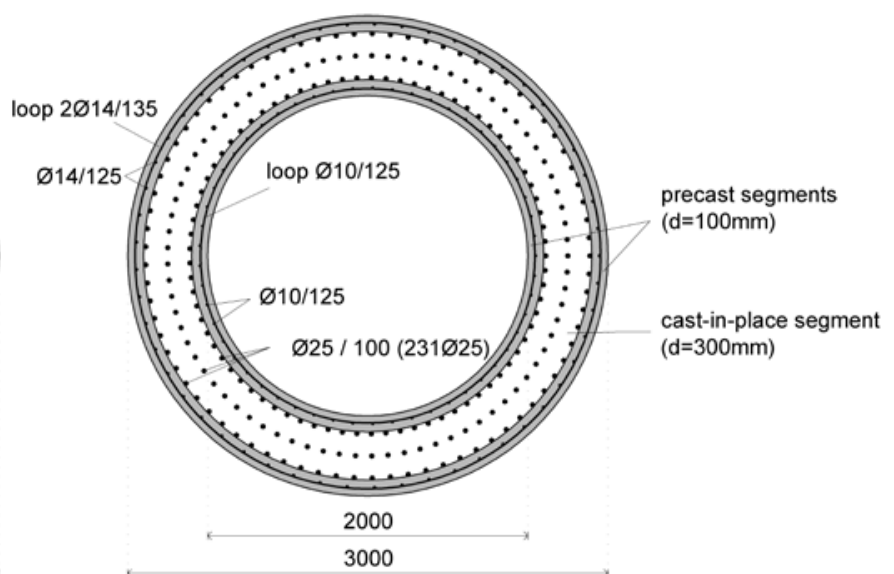

(b)

Figure 13: (a) Reinforcement of piers P1(bottom) and P2(bottom) of the reference bridge (b) Reinforcement of piers P1(bottom) and P2(bottom) of the re-designed bridge. 


\section{EXPANSION OF PREFABRICATION AT THE ABUTMENTS}

Prefabrication can be also exploited in the area of abutments. This implementation contributes to a further increase of the construction speed and to the full standardization of bridges made with the method of prefabrication. In this paragraph, indicative plans of a prefabricated abutment are given, tailored to the case of the examined reference bridge. The prefabricated abutment, due to its size and its geometric complexity, consists of four different kinds of prefabricated products, each in a different quantity. It is assembled in 4 phases. It consists of four parts forming the wall-web of the abutment, four parts forming the back wall, two parts forming the wing-walls (type B) and 2 parts of wing-walls (type A). These parts are assembled in the order they were mentioned (Fig. 14).

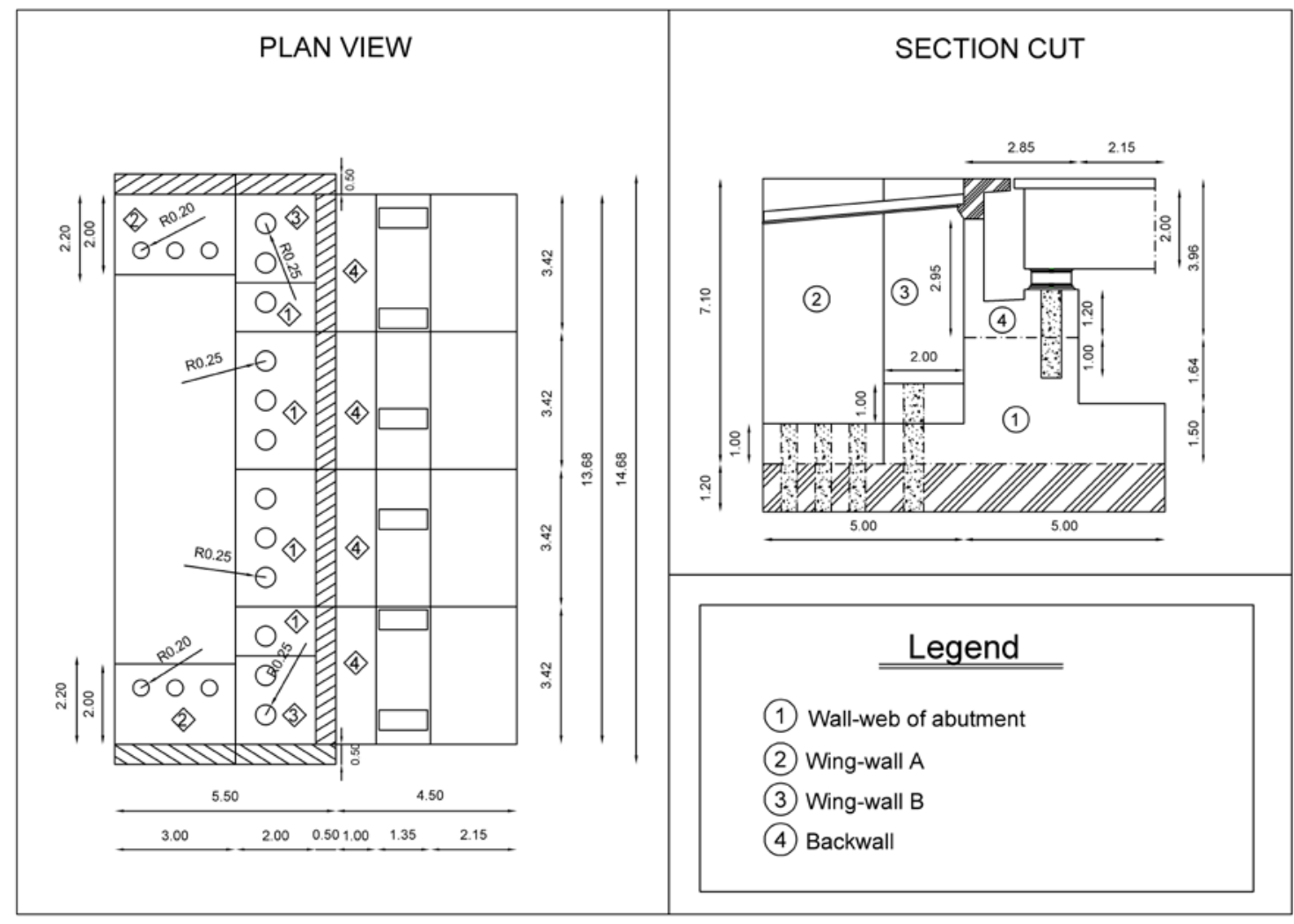

Figure 14: Indicative precast pier assembly drawings.

\section{CONCLUSIONS}

In the present study a method of exploiting prefabrication at piers and abutments of precast bridges is presented. The applicability of the method and the benefits, gained by its application, were examined analytically and experimentally. The main conclusions of the research are the following:

- The segmentation of the piers in parts of equal length and their crossheads in two symmetrical halves provides a manageable outcome in terms of geometry and transferring them in site.

- Similarly, the segmentation of an abutment, which consists of two main parts (the wallweb and the two wing-walls), complies with the above mentioned criteria. 
- Regarding the effects of segmental construction on the mechanical properties of the pier webs, which are the main recipients of seismic action, the presented coarse research concluded that the segmentation resulted in no observable deviation in strength and stiffness from the conventionally constructed piers. Regarding ductility, it is obvious that it does not concern this case because precast bridges reside in non-ductile structures.

\section{ACKNOWLEDGEMENTS}

The authors wish express their gratitude to the precast factory ARMOS S.A. for preparing the specimens necessary for the experimental section of the study and to METE SYSM S.A. for providing the original study of the bridge for the purposes of the present study.

\section{REFERENCES}

[1] F. Leonhardt, Vorlesungen uebermassivbau-Sechster Teil, Springer-Verlag, 1978.

[2] CEN [Comité Européen de Normalisation], EN 1992-1-1: Eurocode 2: Design of Concrete Structures - Part 1-1: General Rules and Rules for Buildings, 2004.

[3] CEN [Comité Européen de Normalisation], EN 1998-2: Eurocode 8: Design of Structures for Earthquake Resistance - Part 2: General Rules, Seismic Actions and Rules for Buildings, 2004.

[4] CEN [Comité Européen de Normalisation], EN 1998-2: Eurocode 8: Design of Structures for Earthquake Resistance - Part 2: Bridges, 2005. 